THE WABASH CENTER

JOURNAL on TEACHING

BOOK REVIEW

\title{
Applying the Scholarship of Teaching and Learning Beyond the Individual Classroom
}

\author{
Jennifer Friberg and Kathleen McKinney, editors \\ Bloomington, IN: Indiana University Press, 2019 \\ (ix +218 pages, ISBN 978-0-253-042835, \$35.00)
}

\begin{abstract}
Applying the Scholarship of Teaching and Learning Beyond the Individual Classroom offers several examples of faculty using methods of Scholarship of Teaching and Learning (SoTL) to improve not only their courses, but also curriculum design, degree programs, and general education learning objectives for students across their campuses. Engaging undergraduate and graduate contexts, this volume offers readers the opportunity to consider courses from a variety of disciplines, engaging course structures; components and assignments; and
\end{abstract} assessment of student learning, student engagement, student learning objectives, and of overall curriculum.

Most faculty are well-trained in their disciplines and poorly trained, if at all, in the administrative aspects of higher education. Accreditation and internal assessment processes offer faculty the opportunity to gauge the effectiveness of what they do in the classroom so that they can continually tweak courses to best serve students according to their curricular and degree needs, the very stuff of SoTL. The skillset required to do this is massive, and Friberg and McKinney offer a glimpse into not only introductory SoTL, but also nine faculty projects engaging these dynamics and analyzing their findings.

This volume would be helpful to faculty engaged in committees and special assignments related to accreditation or to new faculty who have not learned how to think about course design in terms of student learning outcomes within larger degree plan objectives. For example, chapter 4 examines common reading programs through SoTL and how various academic units, including individual courses, engaged with the campus-wide effort to boost student retention and success. Alternatively, the following chapter uses the tools of SoTL to determine necessary skills for preschool educators so that degree programs can better serve their students in preparation for real-world contexts. As faculty seek to integrate digital media into their courses, particularly as more theological higher education moves toward online learning, chapters 1 and 2 offer examples of using nontraditional pedagogies like photography and flipped classrooms to improve student outcomes.

While readers may not progress through this volume cover to cover, it offers a helpful conversation partner to those seeking to freshen their courses. Readers with questions like Are my students learning what I want them to learn? Can I offer a better assignment to assess student learning? or How does my class prepare students for what they'll face in ministry contexts? will find helpful ideas and templates in Fribert and McKinney to help them assess their own work. Rather than seeing SoTL as something external imposed upon faculty, this volume invites educators to consider how SoTL can enrich not only the individual classroom but the entire university or seminary experience and students' real-world experience during and beyond academia. 